\title{
Prospective trials of minor surgical procedures and high-fibre diet for haemorrhoids
}

\author{
M R B KEIGHLEY, P BUCHMANN, S MINERVINI, Y ARABI, J ALEXANDER-WILLIAMS
}

British Medical fournal, 1979, 2, 967-969

\section{Summary and conclusions}

Two hundred and sixteen consecutive patients seen for the first time with symptomatic haemorrhoids entered trials of conservative and minor surgical treatment. They were divided into two groups according to their pretreatment maximal anal pressure.

Patients with pressures of $100 \mathrm{~cm} \mathrm{H}_{2} \mathrm{O}(73.7 \mathrm{~mm} \mathrm{Hg})$ or more (108 patients) were treated by anal dilatation (37), sphincterotomy (34), or high-fibre diet (37). Four and 12 months later anal dilatation had produced significantly better results than sphincterotomy or diet. Furthermore, anal dilatation was the only treatment associated with a significant reduction in anal pressure at four and 12 months. Patients with pressures under $100 \mathrm{~cm} \mathrm{H}_{2} \mathrm{O}$ (108 patients) were treated by rubber-band ligation (35), cryosurgery (36), or diet (37). Four and 12 months later significantly more patients were improved by rubber-band ligation than by cryosurgery or diet.

These results suggest that haemorrhoids in patients with excessive activity of the internal anal sphincter are best treated by anal dilatation and that in all other patients rubber-band ligation is the treatment of choice.

\section{Introduction}

Most patients with symptomatic haemorrhoids may be successfully treated by minor procedures that avoid the need for haemorrhoidectomy. ${ }^{12}$ Treatment is aimed at relieving symptoms rather than improving the appearance of the anal canal. ${ }^{3-5}$ We distinguish two groups of patients with heamorrhoids: (a) young people, usually men, whose principal symptom is bleeding and anal discomfort; and (b) older patients, usually women, in whom prolapse is the principal complaint. ${ }^{6}$ In the

Birmingham General Hospital, Birmingham B4 6NH

M R B KEIGHLEY, MS, FRCS, consultant surgeon

P BUCHMANN, MD, research fellow (present address: Oberarzt University Hospital, Zurich, Switzerland)

S MINERVINI, MD, research registrar (present appointment: surgical registrar, Surgical Clinic V1, University of Rome, Italy)

Y ARABI, MD, FRCS, research fellow (present appointment: senior lecturer, University of Khartoum)

J ALEXANDER-WILLIAMS, MD, FRCS, consultant surgeon first group there is evidence of an overactive internal anal sphincter, while the second usually have a lax anal canal associated with low resting anal pressures. Trials in our unit comparing lateral subcutaneous sphincterotomy with rubberband ligation showed that sphincterotomy produced good results in patients with high anal pressure but tended to precipitate prolapse in the elderly. Conversely, rubber-band ligation was associated with discomfort in patients with an overactive internal sphincter but good results in those with prolapse. ${ }^{7}$ It was concluded that a procedure to reduce anal pressure was most suitable for patients with anal pain and bleeding, whereas fixation of the mucosa was most appropriate for patients with prolapsing piles. Dietary fibre and bulking agents have also been advised for haemorrhoids to avoid excessive straining at stool, ${ }^{\circ}$ but the place of such agents as a principal means of treatment has not been established conclusively. ${ }^{9}$

The aims of this study were to compare a high-fibre diet with minor surgical procedures in patients with symptomatic haemorrhoids. Patients with high resting anal pressures were allocated at random to treatment by anal dilatation, lateral subcutaneous sphincterotomy, or diet. Patients with low resting anal pressures were allocated at random to treatment with rubber-band ligation, cryosurgery, or diet.

\section{Patients and methods}

We studied 216 patients with symptomatic haemorrhoids (154 men and 62 women) for which they had never before been treated in hospital. A total of 108 patients constituted the high-pressure group (maximal resting anal pressure $100 \mathrm{~cm} \mathrm{H} \mathrm{H}_{2} \mathrm{O}(73.7 \mathrm{~mm} \mathrm{Hg}$ ) or more) and the remaining 108 the low-pressure group (maximal resting anal pressure under $100 \mathrm{~cm} \mathrm{H} \mathrm{H}_{2} \mathrm{O}$ ). We used $100 \mathrm{~cm} \mathrm{H}_{2} \mathrm{O}$ as the dividing line since it was almost the same as the median value of anal pressures in another series of patients with haemorrhoids studied under the same conditions in this unit. ${ }^{6}$ We allocated patients to each treatment using two series of numbered randomisation cards stratified for "high" and "low" pressure.

Initial assessment of symptoms and examination findings were recorded on a special data sheet. Maximal resting anal pressures were recorded whenever possible before treatment and four and 12 months later by means of a closed water-filled balloon probe. ${ }^{10}$ The highest pressure was recorded as the maximal anal pressure. Evaluation of treatment included recording the duration of time off work and the incidence of complications, and a symptomatic review at four and 12 months.

Patients allocated to diet were given a high-roughage-diet instruction sheet and a one-month course of Fibranta tablets (Norgine; bran content $8 \mathrm{~g}$ ), two twice daily. Six-finger anal dilatation was performed as a day-case procedure under general anaesthesia but the patients were not given an anal dilator to use themselves. Lateral subcutaneous

TABLE I-Age and sex distribution and main presenting symptoms of patients in the two groups

\begin{tabular}{|c|c|c|c|c|c|c|c|}
\hline & & \multicolumn{3}{|c|}{ High-pressure group $(n=108)$} & \multicolumn{3}{|c|}{ Low-pressure group $(n=108)$} \\
\hline & $\cdot$ & $\begin{array}{c}\text { Anal dilatation } \\
(\mathrm{n}=37)\end{array}$ & $\begin{array}{c}\text { Sphincterotomy } \\
(\mathrm{n}=34)\end{array}$ & $\begin{array}{c}\text { Diet } \\
(\mathrm{n}=37)\end{array}$ & $\begin{array}{l}\text { Rubber-band ligation } \\
\qquad(\mathrm{n}=35)\end{array}$ & $\begin{array}{l}\text { Cryosurgery } \\
(\mathrm{n}=36)\end{array}$ & $\begin{array}{c}\text { Diet } \\
(\mathrm{n}=37)\end{array}$ \\
\hline $\begin{array}{l}\text { Mean age (years) } \pm S D \\
\text { No of men } \quad . . \\
\text { No of women } \quad \therefore \\
\text { Principal presenting syr }\end{array}$ & $\begin{array}{l}\ldots \\
\cdots \\
\text { nptoms: }\end{array}$ & $\begin{array}{l}39 \pm 9 \cdot 1 \\
35 \\
2\end{array}$ & $\begin{array}{c}41+10 \cdot 5 \\
29 \\
5\end{array}$ & $\begin{array}{c}42+10 \cdot 7 \\
35 \\
2\end{array}$ & $\begin{array}{l}49 \pm 4 \cdot 1 \\
19 \\
16\end{array}$ & $\begin{array}{c}48 \pm 7 \cdot 3 \\
24 \\
12\end{array}$ & $\begin{array}{c}47 \pm 11 \cdot 9 \\
12 \\
25\end{array}$ \\
\hline $\begin{array}{ll}\text { Pain } & \ldots \\
\text { Bleeding } & \ldots \\
\text { Prolapse } & \ldots \\
\text { Irritation } & .\end{array}$ & $\begin{array}{l}\cdots \\
\cdots \\
\cdots\end{array}$ & $\begin{array}{r}5 \\
27 \\
0 \\
5\end{array}$ & $\begin{array}{r}10 \\
19 \\
0 \\
5\end{array}$ & $\begin{array}{r}12 \\
19 \\
0 \\
6\end{array}$ & $\begin{array}{r}3 \\
18 \\
11 \\
3\end{array}$ & $\begin{array}{r}6 \\
19 \\
7 \\
4\end{array}$ & $\begin{array}{r}8 \\
19 \\
6 \\
4\end{array}$ \\
\hline
\end{tabular}


TABLE II-Immediate complications after treatment and time spent off work in the two groups

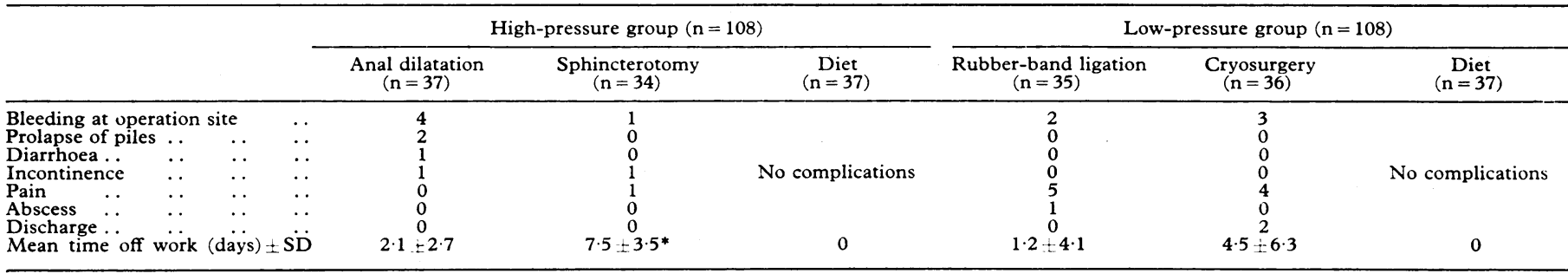

*Compared with anal dilatation: $\mathbf{P}<0.05$.

TABLE III-Clinical results four and 12 months after treatment in the two groups

\begin{tabular}{|c|c|c|c|c|c|c|c|c|}
\hline & & & \multicolumn{3}{|c|}{ High-pressure group $(n=108)$} & \multicolumn{3}{|c|}{ Low-pressure group ( $n=108$ ) } \\
\hline & & & $\begin{array}{l}\text { Anal dilatation } \\
\qquad(\mathrm{n}=37)\end{array}$ & $\begin{array}{l}\text { Sphincterotomy } \\
(\mathrm{n}=34)\end{array}$ & $\begin{array}{c}\text { Diet } \\
(\mathrm{n}=37)\end{array}$ & $\begin{array}{l}\text { Rubber-band ligation } \\
(\mathrm{n}=35)\end{array}$ & $\begin{array}{l}\text { Cryosurgery } \\
(\mathrm{n}=36)\end{array}$ & $\begin{array}{c}\text { Diet } \\
(\mathbf{n}=37)\end{array}$ \\
\hline & & \multicolumn{7}{|c|}{ Results at four months } \\
\hline \multirow{2}{*}{\multicolumn{2}{|c|}{$\begin{array}{l}\text { Asymptomatic } \ldots \\
\text { Improved but some symptoms still present }\end{array}$}} & $\ldots$ & 16 & 5 & 5 & 22 & 10 & 3 \\
\hline & & $\therefore$ & 11 & 8 & 11 & 10 & 15 & 10 \\
\hline \multirow{3}{*}{$\begin{array}{l}\text { No better . . } \\
\text { Required other treatment } \\
\text { No follow-up data available }\end{array}$} & . $\quad$. & .. & $1\} 10^{\circ} *$ & $6\} 43^{\circ}$ & $4\} 41 \%$ & $0\} 3 \%$ & $7\} 31 \%$ & 15\}62\% \\
\hline & $\begin{array}{ll}. \\
.\end{array}$ & $\because$ & $2 \int^{10}$ & $4\}^{40}$ & $7 \int^{710}$ & $\frac{1}{2} \int^{0 !}$ & $\begin{array}{l}4\}^{31} \\
0\end{array}$ & $6\}^{020}$ \\
\hline & & & \multicolumn{6}{|c|}{ Results at 12 months } \\
\hline \multirow{4}{*}{$\begin{array}{l}\text { Asymptomatic . . .. } \\
\text { Improved but some symptoms } \\
\text { No better . . . } \\
\text { Required other treatment } \\
\text { No follow-up data available }\end{array}$} & . $\quad \ldots$ & .. & 11 & 6 & 5 & 16 & 4 & 4 \\
\hline & still present & $\because$ & 14 & & 5 & 7 & 10 & 5 \\
\hline & . $\quad \ldots$ & .. & $5\} 26 \%$ & $12\} 63 \%$ & $13\} 73 \%$ & $3\} 18 \%$ & $\left.{ }^{7}\right\} 56 \%$ & $10\} 72 \%$ \\
\hline & $\begin{array}{ll}. \\
\ldots\end{array}$ & $\because$. & ${ }_{3}^{4} \int^{20+}$ & $9 \int_{1}^{9}$ & $\begin{aligned} 14 \\
0\end{aligned}$ & 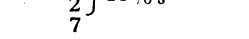 & $11 \int_{4}$ & $\begin{array}{c}13 \\
5\end{array}$ \\
\hline
\end{tabular}

*Compared with sphincterotomy: $\mathbf{P}<0.001$. Compared with diet: $\mathbf{P}<0.005$

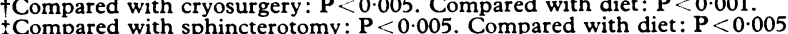

+Compared with sphincterotomy: $\mathrm{P}<0.005$. Compared with diet $: \mathrm{P}<0.005$.
\&Compared with cryosurgery: $\mathrm{P}<0.001$. Compared with diet: $\mathrm{P}<0.001$.

TABLE IV-Subsequent treatment required by patients in the two groups within one year after original treatment

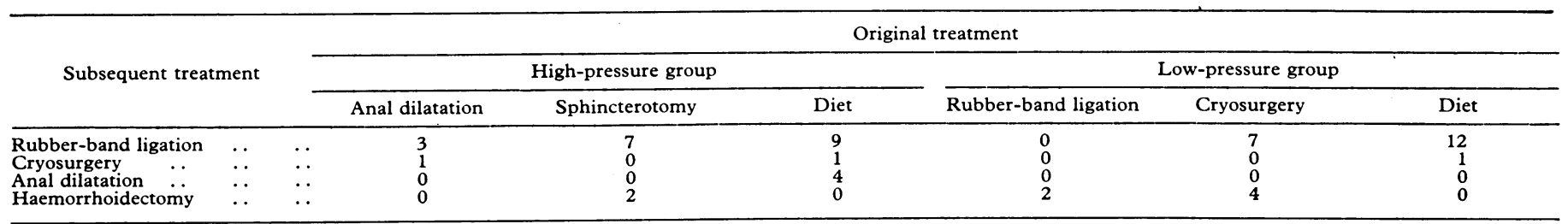

sphincterotomy was performed under local anaesthesia in the operating theatre with a cataract knife. ${ }^{11}$ Rubber bands were applied in the outpatient clinic to the mucosa above haemorrhoids at the 3 o'clock and 8 o'clock positions, ${ }^{12}$ and again, if necessary to control residual haemorrhoids, at the one-month follow-up appointment (10 cases; $29 \%$ ). Cryosurgery was also applied to the mucosa above the principal haemorrhoids using a Clifton protoscope and a fine nitrous-oxide probe. ${ }^{13}$

Table I gives the age and sex distribution and main presenting symptoms of patients in the high-pressure and low-pressure groups. Though the two groups were similar with respect to age and principal presenting symptoms, patients in the high-pressure group were on average 6 to 7 years younger than those with low pressure. Prolapse was never a predominant feature in patients with high anal pressure, whereas it was often recorded in those with lower pressure.

\section{Results}

\section{HIGH-PRESSURE GROUP}

Immediate complications were more common after anal dilatation than after sphincterotomy (table II). Out of five cases of bleeding or haematoma, four occurred after anal dilatation. Minor prolapse was also reported in two patients after this procedure. Temporary incontinence or soiling occurred in one patient after anal dilatation and one after sphincterotomy. Patients remained off work significantly longer after sphincterotomy than after anal dilatation $(P<0.05)$.

Symptomatic review at four months showed that anal dilatation produced significantly better results than either sphincterotomy
$(P<0.001)$ or diet $(P<0.005)$ (table III). Only three patients reported that their symptoms had not been improved or needed other treatment after anal dilatation compared with 10 and 11 patients after sphincterotomy and diet respectively. Similar results were reported one year after treatment (table III). Nine patients had persistent symptoms or needed other treatment after dilatation compared with 21 after sphincterotomy $(P<0.005)$ and 27 after diet $(P<0.005)$. Table IV lists the subsequent treatment given.

Table $\mathrm{V}$ shows the effect of treatment on mean maximal anal pressures at four and 12 months. Analysis of paired data at four months showed a significant reduction in anal pressure after dilatation and sphincterotomy, but at one year only patients treated by dilatation had a significant reduction. High-fibre diet had no influence on maximal anal pressure.

\section{LOW-PRESSURE GROUP}

Immediate complications were similar after rubber-band ligation and cryosurgery (table II). Out of five cases of bleeding, two occurred after rubber-band ligation. Anal pain was reported by nine patients, in one of whom the rubber bands had to be removed under anaesthetic because they had been applied too near the dentate line; this patient subsequently developed a submucous abscess, which discharged spontaneously. Profuse watery discharge was reported in only two cases, both after cryosurgery. Time spent off work was longer after cryosurgery than after rubber-band ligation but the difference was not significant.

At four months the results of band ligation were unquestionably better than those of cryosurgery $(P<0.005)$ and diet $(P<0.001)$, and 
at one year the results continued to favour ligation (table III). Only five patients treated by rubber-band ligation needed alternative treatment or were no better compared with 18 after cryosurgery $(\mathbf{P}<0.001)$ and 23 after diet $(P<0.001)$. All forms of treatment were associated with a small increase in anal pressure, but in none of the groups was the change significant (table V).

TABLE V-Effect of treatment on maximal anal pressures $\left(\mathrm{cm} \mathrm{H}_{2} \mathrm{O}\right)$ at four and 12 months. Values are means $\pm S D\left(100 \mathrm{~cm} \mathrm{H} \mathrm{H}_{2} \mathrm{O}=74 \mathrm{~mm} \mathrm{Hg}\right)$. Numbers of observations given in parentheses

\begin{tabular}{|c|c|c|c|c|}
\hline & \multicolumn{2}{|c|}{ Pressure at 4 months } & \multicolumn{2}{|c|}{ Pressure at 12 months } \\
\hline & Before & After & Before & After \\
\hline & \multicolumn{4}{|c|}{ High-pressure group } \\
\hline \multirow[t]{2}{*}{$\begin{array}{l}\text { Anal dilatation } \\
\text { Sphincterotomy } \\
\text { Diet } \quad . \quad \quad .\end{array}$} & $\begin{array}{ll}\Rightarrow & 141=19 \\
\because & 150=2 . \\
\therefore & 122=10\end{array}$ & $\begin{array}{l}114=32 *(19) \\
122 \div 32+(14) \\
129 \div 45 \quad(16)\end{array}$ & $\begin{array}{l}141=43 \\
132=31 \\
135=47\end{array}$ & $\begin{array}{l}117=27+(10) \\
114 \pm 43 \\
140 \pm 19 \quad(7)\end{array}$ \\
\hline & \multicolumn{4}{|c|}{ Low-pressure group } \\
\hline $\begin{array}{l}\text { Rubber-band ligation } \\
\text { Cryosurgery } \\
\text { Diet } \ldots \\
\text {. }\end{array}$ & $\begin{array}{l}83: 24 \\
85 \div 17 \\
65: 24\end{array}$ & 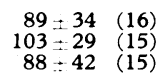 & $\begin{array}{l}65=16 \\
83: 18 \\
85 \square 22\end{array}$ & $\begin{array}{r:rr}82 & 35 & (10) \\
97 & 36 & (7) \\
108 & 43 & (5)\end{array}$ \\
\hline
\end{tabular}

$\begin{array}{ll}* \text { P. } & 0.005 . \\ + \text { P. } & 0.05\end{array}$

\section{Discussion}

We classified these patients according to the maximal anal pressures on their first attendance at our rectal clinic. It might be argued that the choice of $100 \mathrm{~cm} \mathrm{H}_{2} \mathrm{O}(73.7 \mathrm{~mm} \mathrm{Hg})$ is an arbitary division based on a median value in another group of patients with haemorrhoids and that the symptoms associated with excessive internal anal sphincter activity relate to a much smaller group than half of the population. Digital assessment of anal tone is an unreliable indicator of anal pressure, ${ }^{6}$ although failure to introduce two fingers into the anal canal has been suggested as an alternative means of detecting an overactive sphincter. Nevertheless, introducing two fingers into the anal canal was recorded as impossible in only 16 of the 108 patients with high anal pressures. Application of rubber bands and prolonged proctoscopy necessary for cryosurgery may make either procedure difficult in patients with high pressure. Furthermore, sphincterotomy and anal dilatation may precipitate prolapse, particularly in the elderly. ${ }^{14}$

Assessing results one year after treatment was difficult, since many patients had already been discharged from the clinic. We therefore sent a questionnaire to 56 patients who had been discharged, requesting that they return for follow-up if they had continuing symptoms or return the questionnaire if they were satisfied with treatment. Replies were received from 36 patients $\left(64^{\circ}{ }_{11}\right)$. The proportion of patients reviewed by questionnaire was similar in each treatment group. Failure to attend for review was one of the reasons for the small numbers of patients in whom anal pressures were recorded before and 12 months after treatment. Hence we do not attach too much importance to our mañometric results. Furthermore, the small numbers made assessment difficult, particularly as there was considerable variation in maximal anal pressure within individuals studied on different days. Procedures such as proctoscopy and digital examination influence anal pressures. Nevertheless, we were careful to undertake manometry only after the proctoscopic assessment.

We found that anal dilatation gave the best results in the high-pressure group. Anal dilatation is potentially more expensive than sphincterotomy since it requires hospital admission and general anaesthesia. We were therefore disappointed when sphincterotomy undertaken in the outpatient department with local infiltration of lignocaine ${ }^{15}$ provided symptomatic results no better than those of the high-roughage diet. We find that sphincterotomy is more suitable for treating anal fissure ${ }^{16}$ than as primary treatment for haemorrhoids. As diet had no influence on anal pressure it probably has little curative effect, particularly since placebo treatment may be associated with improvement in about a third of patients. ${ }^{9}$

Results in patients with low anal pressure showed that rubber-band ligation is the procedure of choice. The long-term (five-year) results of band ligation are satisfactory in over $80 \%$ of patients in our clinic. ${ }^{12}$ Few patients require haemorrhoidectomy but up to $10^{\circ}$, experience transient anal pain or bleeding within a week of treatment, and patients should be warned of this. It is important to emphasise to patients that a second course of band ligation may be necessary. Results of cryosurgery were disappointing, and, as the procedure is time-consuming ard requires cumbersome apparatus, we no longsi wo the cryoprobe.

P Buchmann was supported by a fellowship from the Swiss National Science Research Foundation, and S Minervini by the British Council. Y Arabi received support from a research grant awarded by the West Midlands Regional Health Authority.

Requests for reprints should be addressed to: Mr M R B Keighley, The General Hospital, Steelhouse Lane, Birmingham B4 6NH.

\section{References}

${ }^{1}$ Allgower, M, Clinics in Gastroenterology, 1975, 4, 608.

${ }^{2}$ Lord, P H, British fourna! of Surgery, 1969, 56, 747.

${ }^{3}$ Anscombe, A R, Hancock, B D, and Humphreys, W V, Lancet, 1974, 2, 250.

4 Jones, C B, and Schofield, P F, Proceedings of the Royal Society of Medicine, 1974, 67, 51 .

${ }^{5}$ Macintyre, I M C, and Balfour, T W, Lancet, 1972, 1, 1094.

${ }^{6}$ Arabi, Y, Alexander-Williams, J, and Keighley, M R B, American fournal of Surgery, 1977, 134, 608.

Arabi, Y, et al, British fournal of Surgery, 1977, 64, 737.

${ }^{8}$ Alexander-Williams, J, and Crapp, A R, Clinics in Gastroenterology, 1975, 4, 595.

${ }^{9}$ Broader, J H, Jones, I F, and Alexander-Williams, J, British fournal of Surgery, 1974, 61, 142

10 Hancock, B D, and Smith, K, British Fournal of Surgery, 1975, 62, 833.

11 Notaras, M J, Eritish Fournal of Surgery, 1971, 58, 96.

12 Steinberg, D M, Liegois, H, and Alexander-Williams, J, British fournal of Surgery, 1975, 62, 144.

${ }^{13}$ Kaufman, H D, British Fournal of Surgery, 1976, 63, 462.

14 Bates, T, British Medical fournal, 1972, 2, 505.

${ }^{15}$ Gatehouse, D, Arabi, Y, and Keighley, M R B, Proceedings of the Royal Society of Medicine, 1978, 71, 29.

${ }^{16}$ Marby, M, et al, Diseases of the Colon and Rectum. In press.

(Accepted 14 August 1979)

ONE HUNDRED YEARS AGO Her Majesty the Queen has been graciously pleased to institute a new order, the order of $\mathrm{St}$ Katherine. The order is to be reserved as a reward of merit for those nurses who have distinguished themselves by long service and good conduct. The first installation was held on Wcdnesday afternoon, in the Board Room of the Westminster Hospital, when the order of St Katherine was conferred on three of the nurses of the institution, in the presence of a large and distinguished company. The proceedings were opened by Sir Rutherford Alcock, who stated that each member of the order would receive an honorarium of $£ 50$ per annum during three years, and that a like sum would be paid to the Lady Stanley Nursing Institute for their board and maintenance. At the expiration of three years, the annuity would cease, and a fresh election be made. The title of nurse of the order of St Katherine would, however, be retained. The salary of $£ 50$ a-year is to be quite independent of any income the nurse may receive from the hospital or elsewhere. The St Katherine's nurses will at all times hold themselves in readiness to. attend the poor or sick, at the command of Her Majesty, the patron of the Order, without further pay or gratuity. The Dean of Westminster gave a brief history of the St Katherine's Hospital, which was named after St Katherine of Alexandria, who suffered martyrdom in the fourth century by torture on a wheel. After a few words from Lord Hatherley, the ceremony of installation commenced. The badge of the Order was placed on the left arm of each of the recipients. We believe that the Order will shortly be conferred on seven other nurses. The maintenance of the ten will involve a cost of $£ 1000$ a year. (British Medical fournal, 1879.) 